\title{
PROPANOL CLUSTERING IN ARGON MATRIX: 2D FTIR CORRELATION SPECTROSCOPY
}

\author{
V. BALEVICIUS, ${ }^{1}$ V. SABLINSKAS,${ }^{1}$ I. DOROSHENKO,${ }^{2}$ V. POGORELOV ${ }^{2}$ \\ ${ }^{1}$ Vilnius University \\ (9-3, Sauletekio Al., LT-10222 Vilnius, Lithuania; e-mail: vytautas. balevicius@ff. vu. lt) \\ ${ }^{2}$ Taras Shevchenko National University of Kyiv \\ (4, Academician Glushkov Ave., Kyiv, Ukraine)
}

PACS 37.10.Pq; 36.40.Mr

(C) 2011

\begin{abstract}
The dynamic FTIR spectra of propanol in the argon matrix have been measured using a thermal perturbation by heating the sample from $T=11 \mathrm{~K}$ to $30 \mathrm{~K}$ stepping by $1 \mathrm{~K}$. The $2 \mathrm{D}$ Fourier-transform infrared (FTIR) absorption correlation analysis has been carried out, the main attention being concentrated to the region of propanol $\mathrm{O}-\mathrm{H}$ stretching vibrations at $3000-3700 \mathrm{~cm}^{-1}$. The peaks of monomers, two conformers of open dimer, and the cyclic structures from a dimer to a pentamer have been resolved and studied in more details. Analyzing the dependences of the integral band intensities of various aggregates on the temperature, it has been deduced that monomers and dimers act in the initial clustering stage as the main "building units" whose diffusion sustains the formation of the higher $\mathrm{H}$-bond structures in the matrix. The full width at half height (FWHH) for each band has been processed as a function of the aggregation number $(n)$. It is found that the FHWW is a perfectly linear function of $n$ for all cyclic aggregates $n \geq 2$. The resonance broadening has been proposed to be the most reliable mechanism for the formation of diffuse $\mathrm{O}-\mathrm{H}$ stretching bands in the matrix isolated clusters.
\end{abstract}

\section{Introduction}

The growing interest in the clustering phenomena that produce partially ordered atomic or molecular structures is due to the recent developments and challenges in studies on modern multifunctional materials, heterogeneous systems, nanotechnologies, basic biochemical research, etc. [1-3].The simplest alcohols, whose molecules tend to associate into hydrogen bond networks and to form a broad variety of H-bond aggregates, can be considered as ones of most convenient models to investigate the fine structural changes, cooperativity effects, photoinduced- and other processes in molecular systems sized over the mezoscopic scale. The most significant results have been obtained using the vibrational spectroscopy (FTIR absorption and Raman ones) together with various trapping/isolation techniques, e.g., in solid matrices, droplets, jets, etc. [4-12]. This is mainly because the isolation and the spectral acquisition at very low temperatures determine the appearance of narrow signals with minimal overlaps of the spectral bands. Hence, it provides the possibility to study the properties of individual clusters of different sizes. However, some $\mathrm{H}$-bond bands are much broader having the FWHH of the order of $\sim 10^{2} \mathrm{~cm}^{-1}$ even under these conditions. The mechanisms of formation of the diffuse band and its structure are very complex [13-16], still looking to be rather far from being a definitely solved problem.

Therefore, the purpose of the present study was to obtain the FTIR spectra of propanol molecules trapped in the Ar matrix at the continuously increasing temperature stepping by $1 \mathrm{~K}$, from $T=11 \mathrm{~K}$ to $30 \mathrm{~K}$, i.e., up to the onset of the matrix evaporation at $31 \mathrm{~K}$. The whole set of spectral data obtained in this way is then used to construct the so-called dynamic spectra and to process them applying the 2D correlation analysis [17-19]. It is expected that the obtained results will provide a valuable additional information on: (i) the processes of molecular clustering at the very initial stage; and (ii) the mechanisms of broadening of $\nu \mathrm{O}-\mathrm{H}$ absorption bands of the H-bonded aggregates.

\section{Experimental}

The infrared spectra of propanol trapped in the $\mathrm{Ar}$ matrix were registered at the Laboratory of Fouriertransform infrared (FTIR) spectroscopy at the Vilnius University. The gas mixture was prepared by standard manometric techniques. The mixture of gaseous propanol and Ar in approx. ratio 1:500 was deposited at $11 \mathrm{~K}$ at an average $4 \mathrm{mmol} / \mathrm{h}$ flow for $1 \mathrm{~h}$ onto a CsI window. FTIR absorption spectra were measured at different temperatures from $11 \mathrm{~K}$ to $31 \mathrm{~K}$ with a $1-\mathrm{K}$ step using a Bruker IFS 113 spectrometer equipped with a liquid- $\mathrm{N}_{2}$-cooled mercury cadmium telluride (MCT) detector at a resolution of $1 \mathrm{~cm}^{-1}$ in the region $500-5000$ $\mathrm{cm}^{-1}$. In total, 128 scans were averaged for each spec- 


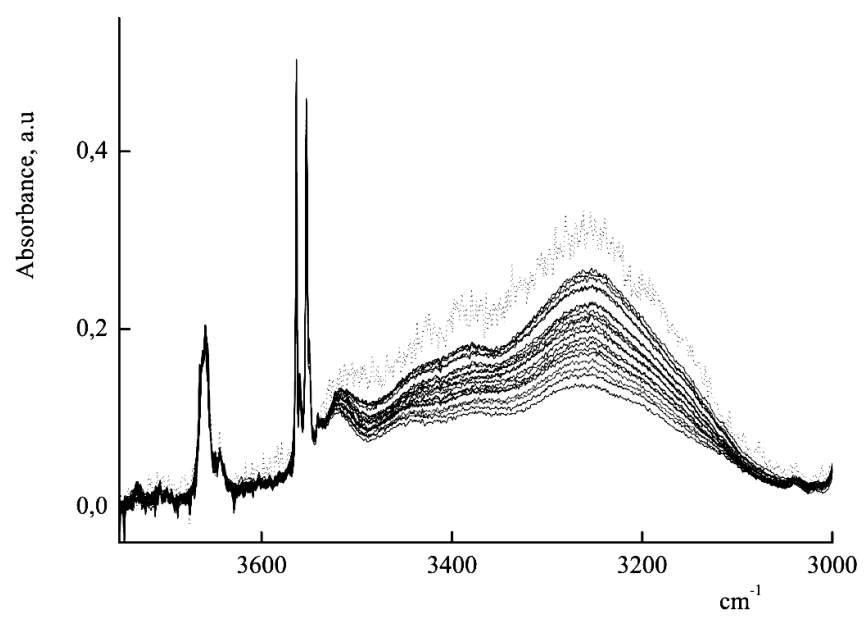

Fig. 1. FTIR spectra of propanol in the argon matrix in $\mathrm{O}-\mathrm{H}$ stretching region over the temperature range 11-30 K (from bottom to upper, by stepping $\Delta T=1 \mathrm{~K}$ ). The very upper spectrum (the onset of matrix evaporation at $31 \mathrm{~K}$ ), shown by the dot line, was excluded from further consideration

trum. An additional smoothing of spectra during the 2D correlation analysis was performed (see details below).

\section{Results and Discussion}

The dynamic spectra for the 2D correlation analysis are constructed using the spectral intensity variation upon an external perturbation such as a mechanical deformation, temperature, or concentration [17-19]. Very significant "composition-induced" changes in the FTIR spectra of propanol in the Ar matrix indeed are observed at various (from $1 / 300$ to $1 / 150$ ) matrix ratios [4]. However, it is obvious that the continuous perturbation of spectra using the "concentration" as the external variable is hardly to be precisely realized in the matrix isolation experiments. Therefore, a "thermal" perturbation has been chosen in the present work as more preferable.

The FTIR spectra (raw spectra or spectrum vectors) $I_{j}(\omega)=I\left(\omega, T_{j}\right), j=1, . ., m$ of propanol in the argon matrix have been measured by heating the sample from $T=11 \mathrm{~K}$ to $30 \mathrm{~K}$, till the argon matrix starts to evaporate at $31 \mathrm{~K}$, with $1 \mathrm{~K}$ step. Above $45-50 \mathrm{~K}$, the matrix evaporates extremely intensively, and the very diffuse $\nu \mathrm{O}-\mathrm{H}$ band typical of the condensed state of neat alcohol is formed [14]. The main attention was given to the region of propanol $\mathrm{O}-\mathrm{H}$ stretching vibrations at the range $3000-3700 \mathrm{~cm}^{-1}$ (Fig. 1).

The dynamic spectrum is formally defined $[18,19]$ as

$I_{d}(\omega, t)=\left\{\begin{array}{l}I(\omega, t)-I_{0}(\omega), \quad-\Delta T / 2 \leq t \leq \Delta T / 2, \\ 0, \quad \text { otherwise }\end{array}\right.$

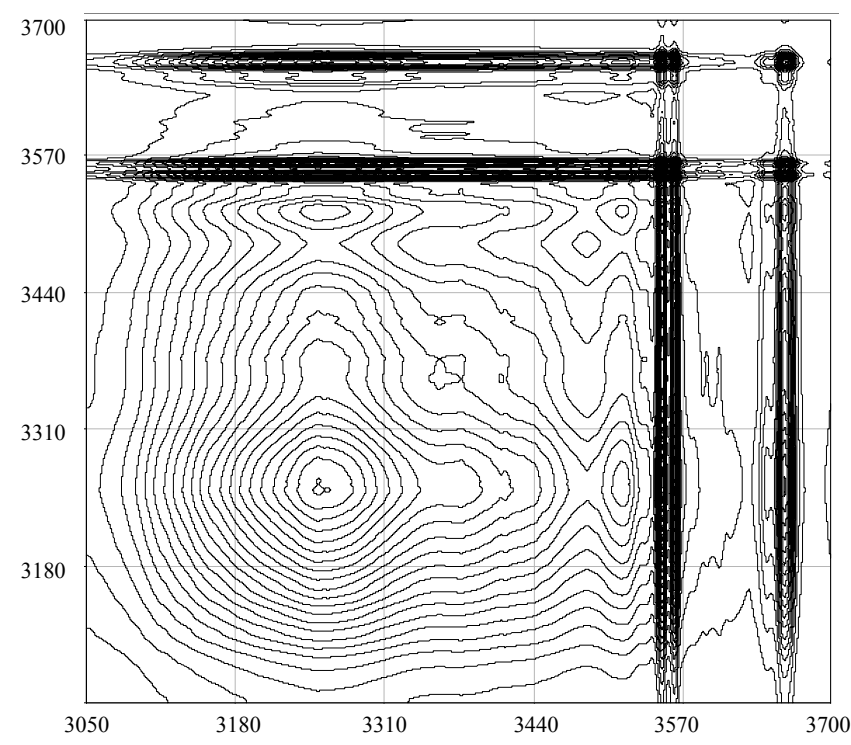

Fig. 2. 2D synchronous FTIR correlation spectrum of propanol in the argon matrix in the $\nu \mathrm{O}-\mathrm{H}$ region

where $I_{0}(\omega)$ is called as the reference spectrum. Its selection is somehow arbitrary. In most cases, $I_{0}(\omega)$ is set to be

$$
I_{0}(\omega)=\frac{1}{\Delta T} \int_{-\Delta T / 2}^{\Delta T / 2} I(\omega, t) \mathrm{d} t
$$

i.e., the mean of spectrum vectors averaged over the whole range of external perturbation $(\Delta T)$. However, if one has a series of experiments with stable baseline, or the baseline is well defined, the choice of the reference does not crucially influence the results of $2 \mathrm{D}$ correlation analysis [20]. Therefore in the present work, the original spectra were baseline-corrected, and then the zero absorbance was used as the reference spectrum [19]. The $\nu \mathrm{C}-\mathrm{H}$ bands were found to remain practically unchanged over the whole temperature range. This indicates that the evaporation of propanol at such rather "soft" heating $(11-30 \mathrm{~K})$ is negligible, and thus no additional renormalization of intensities was necessary. Only the additional smoothing of spectra was performed with the Mathcad software package using the "ksmooth" function, which applies a Gaussian kernel to create weighted averages of the absorption values.

The synchronous 2D correlation spectrum (Fig. 2) was obtained by the inner product of two spectrum vectors

$\Phi\left(\omega_{1}, \omega_{2}\right)=\frac{1}{m-1} \sum_{j=1}^{m} I_{d j}\left(\omega_{1}\right) I_{d j}\left(\omega_{2}\right)$, 


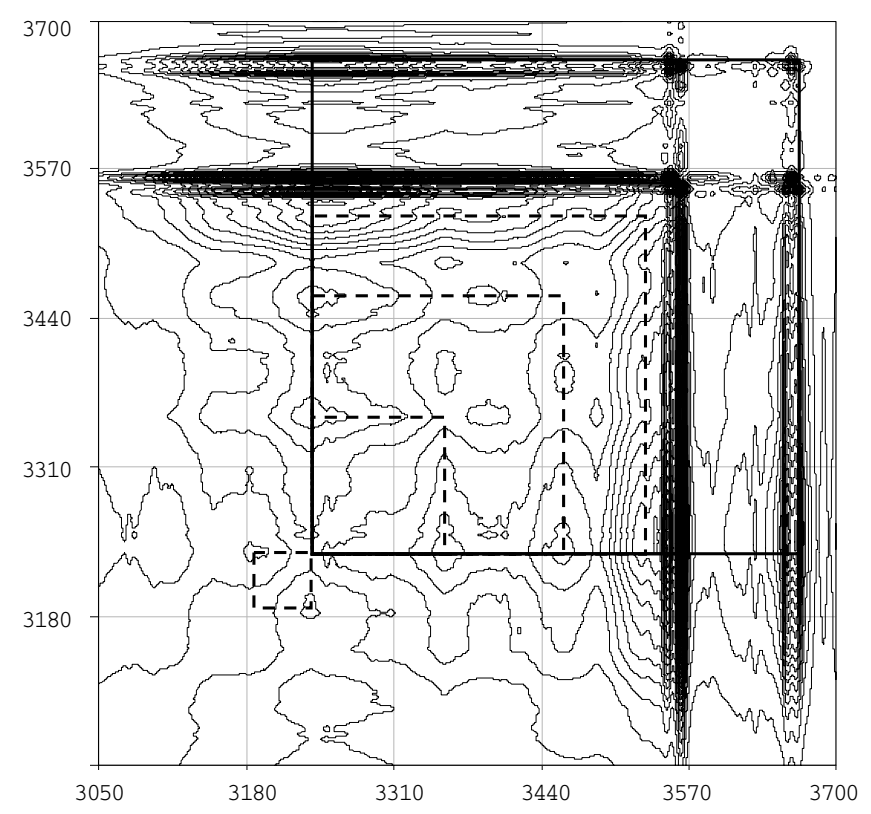

Fig. 3. 2D asynchronous FTIR correlation spectrum of propanol in the argon matrix in the $\nu \mathrm{O}-\mathrm{H}$ region

while the asynchronous correlation spectrum (Fig. 3) was calculated by a cross product of the spectrum vector and its Hilbert transform $H_{d j}[18]$ :

$\Psi\left(\omega_{1}, \omega_{2}\right)=\frac{1}{m-1} \sum_{j=1}^{m} I_{d j}\left(\omega_{1}\right) H_{d j}\left(\omega_{2}\right)$.

The presence of diagonal- and cross peaks in the $2 \mathrm{D}$ correlation maps together with the sign of their intensities allows one to evaluate the number of overlapped "monochromatic" signals, as well as their approximate positions in spectra [17]. The interpretation of the 2D maps (Figs. 2 and 3) was based on the Noda's rules [17-19].

The general trend in the assignment of the alcohols $\mathrm{H}-$ bond bands $\left(3000-3600 \mathrm{~cm}^{-1}\right)$ most frequently found in the literature looks like an aggregation followed by a red shift of spectral bands. Roughly speaking, the higher the aggregation, the lower the band frequency. It seems that it has no alternative at the present state of art. It is also no sense to make efforts getting into the origin of all relatively weak bands while even the origin of the strongest bands in this region is not always unambiguous in the literature.

Hence, the main peaks, resolved and further studied in more details, are: $3660( \pm 0.1)$ and $3643(1) \mathrm{cm}^{-1}$ (both of monomers); 3564(0.1) and $3553(0.1) \mathrm{cm}^{-1}$ (two conformers (?) of an open dimer); 3521(3), 3444(3), 3376(5)

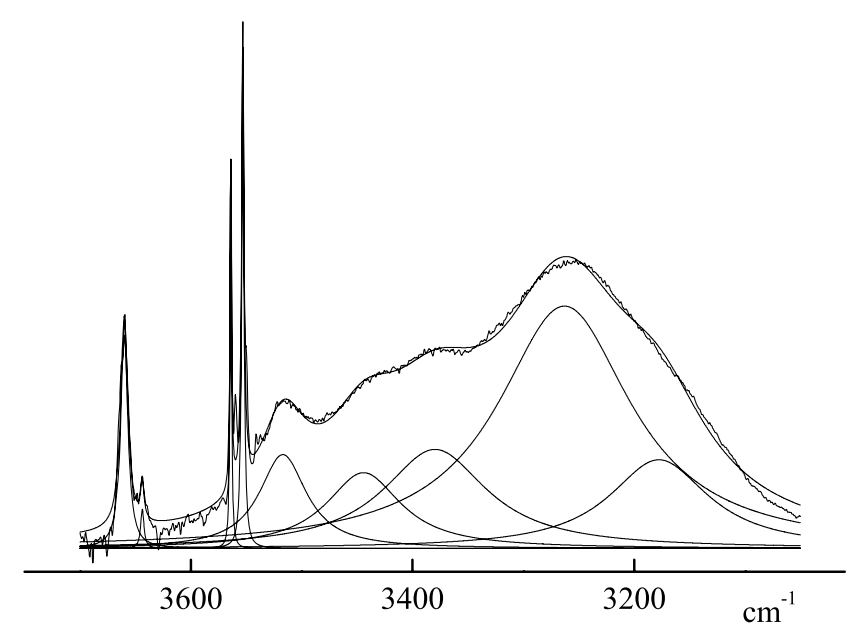

Fig. 4. Non-linear curve fitting of the $\nu \mathrm{O}-\mathrm{H}$ spectral contour by Lorentz functions ( $T=27 \mathrm{~K}$, as an example). The maximum positions obtained from the cross peaks in the $2 \mathrm{D}$ correlation analysis were used as the zero-order approach for the fitting parameters

and $3264(4) \mathrm{cm}^{-1}$ (cyclic structures from a dimer to a pentamer, respectively). The most red-shifted band, following this scheme, should be attributed to the propanol clusters of the highest order. Namely, the extremely broad feature at ca $3178 \pm 4 \mathrm{~cm}^{-1}$ hidden under the envelope of other H-bond bands can be attributed to some 'pulp' - i.e. highly disordered H-bond manifolds. It is practically not detectable in the synchronous spectrum (Fig. 2); however, it can be easily traced in the asynchronous one (Fig. 3). The presence of maybe the same band at ca $3200 \mathrm{~cm}^{-1}$ was noted in [4], and it was assigned to higher polymers. On the other hand, the fact that the band maximum positions vary from \pm 0.1 to $\pm 5 \mathrm{~cm}^{-1}$ (the values given in the brackets above), when the temperature increases from 11 to 30 $\mathrm{K}$, indicates that these spectral components are not truly "monochromatic". Some other much more subtle effects within the aggregates may cause the observed drift of the band maximum with temperature. This also can be one of the factors reasoning the doubing of some cross peaks in the $2 \mathrm{D}$ maps (Figs. 2 and 3), i.e. the peaks are not perfectly defined. The above-mentioned maximum positions were further used as the zero-order approach in the non-linear curve fitting by Lorentz functions (Fig. 4).

The most perfectly defined cross peaks appear in the asynchronous spectrum between the signals of monomers, open dimers, and those assigned to higher aggregates (Fig. 3). It can be concluded that monomers and dimers in the initial clustering stage are the main "building units", whose diffusion sustains the formation of higher H-bond aggregates. This process is rather 


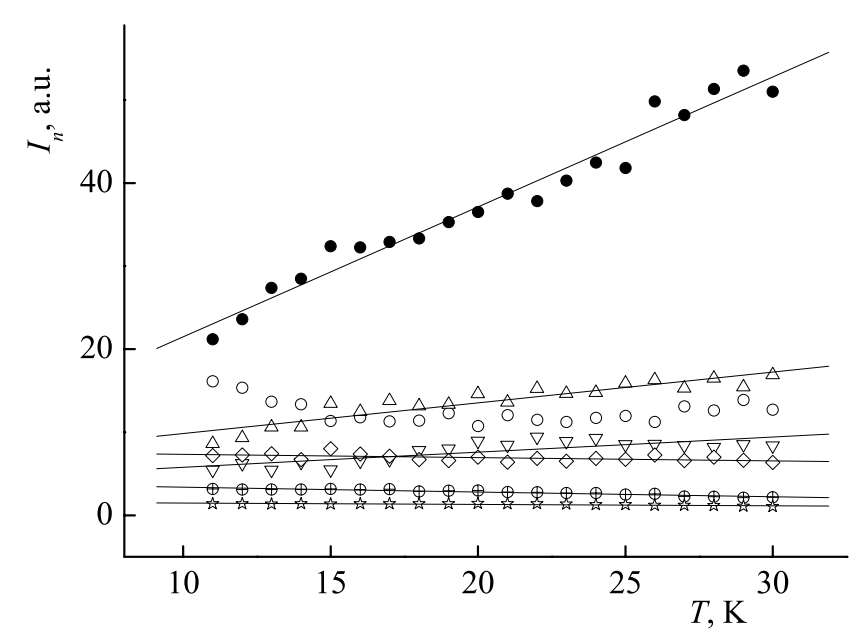

Fig. 5. Temperature dependences of the integral intensities of the monomer and H-bond aggregate bands: o - the band at 3178 $\mathrm{cm}^{-1}$, i.e. the "pulp" or highly disordered higher associates; • 3264 (pentamer); $\triangle-3376$ (tetramer); $\nabla-3444$ (trimer); $\diamond-3521$ (cyclic dimer); $\oplus-3660 \mathrm{~cm}^{-1}$ (monomer) and $\star-$ the average value $(I(3553)+I(3564)) / 2$, i.e. the open dimer band

clearly pronounced on the slopes of the temperature dependences of the integral intensities of the corresponding bands (Fig. 5). Namely, the slopes of $I_{n}$ vs. $T$ are negative for the monomer and dimer bands, whereas they are positive for higher aggregates.

The matrix softening with increase in the temperature and, thus, the opening of more channels for molecular diffusion lead to the increasing discharge of the "monomeric" $\left(A_{1}\right)$ and "dimeric" $\left(A_{2}\right)$ states by the elementary reactions $A_{1}+A_{n-1} \rightarrow A_{n}$ and $A_{2}+A_{n-2} \rightarrow$ $A_{n}$. Irreversibility of kinetic processes in the matrices does not let to refill these states (monomers and dimers) by thermal chemical equilibrium, as it is common for the gases and the liquid solutions. It is notable that, in the case of the argon matrix, it seems that the Ar matrix is not enough spongy for the active diffusion of higher $(n \geq 3)$ H-bond aggregates in the temperature range $(T \leq 30 \mathrm{~K})$. Thus, these higher aggregates behave during the clustering in the Ar matrix as rather passive "targets" linking mobile monomers and dimers, which hit in the same matrix cavity. The observed tendency - the higher the aggregation number $(n)$, the steeper the increase of the intensities $\left(I_{n}\right)$ of the corresponding bands with the temperature (Fig. 5) - may be caused by the entropic (combinatorial) factor, i.e. more possible ways to compose the $n$-meric structure $(\sim n !)$. Moreover, the increase of the individual absorption coefficients of $A_{n}$ aggregates due to the $\mathrm{H}$-bonding can give an additional

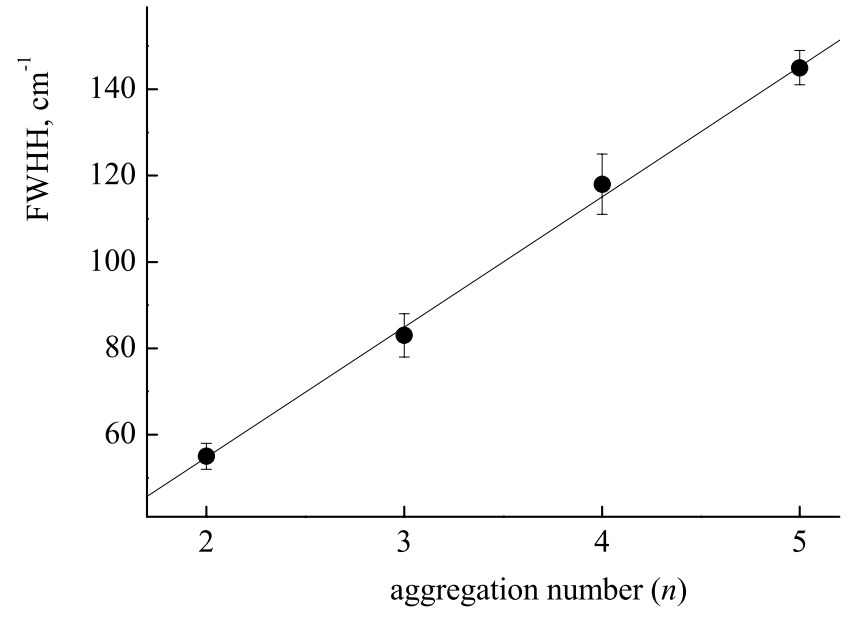

Fig. 6. On the resonance broadening mechanism: the correlation between propanol aggregation numbers and the FWHH of the $\nu \mathrm{O}-$ $\mathrm{H}$ bands of corresponding $\mathrm{H}$-bond aggregates

contribution to the observed steepening of $I_{n}=f(T)$ (Fig. 5).

As was already mentioned in Introduction, elucidating the mechanisms of the broadening of H-bond bands seems to be far from a definitely solved problem. On that score, the most valuable results could be obtained by analyzing the dependences of the band widths (FWHH) of the propanol H-bond aggregates in the Ar matrix on the temperature (Fig. 6). The earlier proposed concept that the $\nu \mathrm{O}-\mathrm{H}$ band widths of alcohol aggregates in matrices are mainly determined by the vibrational dephasing due to the H-bond breaking processes [14] should be revised in the light of these novel observations presented in Figs. 5 and 6 and discussed just above. Namely, due to very low temperatures and the irreversibility of kinetic processes, the H-bond aggregates are kept tight in matrix cavities. It is obvious that, under these conditions, the time constants of H-bond breaking and reformation must be much higher that those (viz., hundreds of fm, up to several ps) evaluated from the ultrafast spectrometric experiments on alcohols in $\mathrm{CCl}_{4}$ solutions at ambient temperatures $[15,16]$.

Another $\nu \mathrm{O}-\mathrm{H}$ band broadening concept, which is based on the FWHH data presented in Fig. 6, can be proposed. First of all - the FHWWs (all, except the band at $3178 \mathrm{~cm}^{-1}$, assigned to the disordered H-bond manifolds, excluded from further consideration) are temperatureindependent. Hence, the width of these bands cannot be determined by the vibrational dephasing due to the $\mathrm{H}$-bond breaking, because the last is a strongly temperature depending process. Furthermore, the FHWW values for each band were statistically averaged over the 
whole temperature range (11-30 K, Fig. 6) and then processed as functions of the aggregation number $(n)$ by the linear regression analysis. It was found that the FHWW is perfectly linear function of $n$ for all cyclic aggregates $n \geq 2$. This is a well-defined feature of the resonance broadening. The resonance interactions were analyzed in the frame of the simple quantum oscillator model [21], and it was deduced that their contribution to the width of a spectral band depends linearly, indeed, on the number of oscillators per unit volume. In the present case of propanol clustering in the Ar matrix, this would mean the proportionality to the number of identical $\mathrm{O}-\mathrm{H}$ oscillators per cluster, i.e. the aggregation number.

\section{Conclusions}

1. The dynamic FTIR spectra of propanol isolated in the solid argon matrix have been measured using the temperature as an external perturbation. The samples were heated from $T=11 \mathrm{~K}$ to $30 \mathrm{~K}$ stepping by $1 \mathrm{~K}$. The 2D FTIR absorption correlation analysis has been carried out, the main attention being concentrated to the spectral region of propanol $\mathrm{O}-\mathrm{H}$ stretching vibrations at $3000-3700 \mathrm{~cm}^{-1}$. The bands of a monomer, two conformers of an open dimer, as well as the cyclic structures from a dimer to a pentamer, have been resolved and studied in more details.

2. Analyzing the temperature dependences of the integral band intensities of various aggregates, it has been deduced that, at the initial clustering stage, monomers and dimers are the main "building bricks," whose diffusion sustains the formation of higher H-bond structures. The Ar matrix at temperatures $T \leq 30 \mathrm{~K}$ is not spongy enough for the active diffusion of higher $(n \geq 3)$ H-bond aggregates.

3. The full width at half height (FWHH) values for each band have been processed as functions of the aggregation number $(n)$, and it is found that the FHWW is a perfectly linear function of $n$ for all cyclic aggregates $n \geq 2$. The novel $\nu \mathrm{O}-\mathrm{H}$ band broadening concept - the resonance broadening that is more reliable than that of vibrational dephasing due to the $\mathrm{H}$-bond breaking processes, has been proposed.

The Lithuanian Science Council and the Ministry of Science and Education of Ukraine are kindly acknowledged for the support of the international research project "Spectroscopy of novel multifunctional compositions producing nanostructures" (2009-2010). Prof. Martin Suhm (Göttingen University, Germany) and Dr.
Joze Grdadolnik (National Institute of Chemistry, Ljubljana, Slovenia) are thanked for comments and stimulating discussions.

1. Atomic and Molecular Cluster Research, edited by Y.L. Ping (Nova Science, New York, 2006).

2. P.G. Reinhard and E. Suraud, Introduction to Cluster Dynamics (Wiley-VCH, Weinheim, 2004).

3. Nanoparticles: from Theory to Application, edited by G. Schmid (Wiley-VCH, Weinheim, 2004).

4. N. Michniewicz, A.S. Muszynski, W. Wrzeszcz et al., J. Mol. Struct. 887, 180 (2008).

5. Z. Mielke, S. Coussan, K. Mierzwicki et al., J. Phys. Chem. A 110, 4712 (2006).

6. R. Wugt Larsen and M.A. Suhm, J. Chem. Phys. 125, 15314 (2006).

7. T.N. Wassermann, P. Zielke, J.J. Lee, C. Cezard, and M.A. Suhm, J. Phys. Chem. A 111, 7437 (2007).

8. C. Emmeluth, V. Dyczmons, T. Kinzel, P. Botschwina, M.A. Suhm, and M. Yanez, Phys. Chem. Chem. Phys. 7, 991 (2005).

9. M. Behrens, R. Frochtenicht, M. Hartmann, J.G. Siebers, U. Buck, and F. Hagemeister, J. Chem. Phys. 111, 2436 (1999).

10. R.A. Provencal, J.B. Paul, K. Roth et al., J. Chem. Phys. 110, 4258 (1999).

11. S. Coussan, V. Brenner, J.P. Perchard, and W.Q. Zheng, J. Chem. Phys. 113, 8059 (2000).

12. S. Coussan, Y. Bouteiller, A. Loutellier et al., Chem. Phys. 219, 221 (1997).

13. V. Pogorelov, L. Bulavin, I. Doroshenko, O. Fesjun, and O. Veretennikov, J. Mol. Struct. 708, 61 (2004).

14. V. Pogorelov, I. Doroshenko, P. Uvdal, V. Balevicius, and V. Sablinskas, Mol. Phys. 108, 2165 (2010).

15. K. Gaffney, P. Davis, I. Piletic, N.E. Levinger, and M.D. Fayer, J. Phys. Chem. A 106, 12012 (2002).

16. K. Gaffney, I. Piletic, and M.D. Fayer, J. Phys. Chem. A 106, 9428 (2002).

17. I. Noda and Y. Ozaki, Two-Dimensional Correlation Spectroscopy: Applications in Vibrational and Optical Spectroscopy (Wiley, Chichester, 2004).

18. I. Noda, Appl. Spectrosc. 54, 994 (2000).

19. I. Noda, Appl. Spectrosc. 47, 1329 (1993).

20. J. Grdadolnik, private communication. 
21. A.B. Pipard, The Physics of Vibration. The Simple Vibrator in Quantum Mechanics (Cambridge Univ. Press, Cambridge, 1983).

Received 21.01.11

\section{КЛАСТЕРИЗАЦІЯ ПРОПАНОЛУ В АРГОНОВІЙ}

МАТРИЦІ: 2D КОРЕЛЯЦЙНА

FTIR-СПЕКТРОСКОПІЯ

В. Балявічус, В. Шаблінскас, I. Дорошенко, В. Погорелов

$\mathrm{P}$ е 3 ю м е

Зареєстровано динамічні фур'є-спектри інфрачервоного поглинання пропанолу в аргоновій матриці при нагріванні зразка від $T=11 \mathrm{~K}$ до $T=30 \mathrm{~K}$ із кроком $1 \mathrm{~K}$. Проведено $2 \mathrm{D}$ кореляційний аналіз фур'є-спектрів інфрачервоного поглинан- ня, головну увагу приділено області валентних коливань О-Н групи (3000-3700 см $\left.{ }^{-1}\right)$. Виділено і докладно розглянуто максимуми поглинання, що відповідають мономерам, двом конформерам лінійних димерів, а також циклічним структурам від димера до пентамера. Шляхом аналізу температурної залежності інтегральних інтенсивностей смуг, що відповідають різним утворенням, було виявлено, що на початковому етапі кластеризації основними "цеглинками" є мономери і димери, у результаті дифузії яких у матриці утворюються Н-зв'язані кластери вищих порядків. Побудовано залежність значення повної ширини на половині висоти (FWHH) для кожної смуги від розміру кластера $(n)$ і показано, що FHWW виявляється ідеальною лінійною функцією від $n$ для всіх циклічних кластерів $n \geq 2$. У ролі найбільш імовірного механізму формування дифузійних смуг О-Н коливань кластерів пропанолу, що ізольовані у матриці, було запропоновано резонансне уширення. 